\title{
ASSENTAMENTOS RURAIS NO SUDESTE GOIANO: expressões (i)materiais da (re)territorialização camponesa ${ }^{1}$
}

\section{ASSENTAMENTOS RURAUX DANS LE SUD-EST DE L'ÉTAT DE GOIÁS: expressions (i)mmatérielles de la (re)territorialisation paysanne}

\author{
Rafael de Melo Monteiro \\ Doutor em Geografia/UNESP/Presidente Prudente. Professor EBTT/IFG/Águas Lindas. \\ rafael.monteiro@ifg.edu.br
}

Mas eu falei: "Eu vou pro acampamento, só que tem uma coisa: de lá eu só saio pra terra”.
(Entrevistada 2, 51 anos, Assentamento Olga Benário/Ipameri/GO, 15/03/2015)

\section{Resumo}

O objetivo deste artigo é compreender o processo de (re)territorialização camponesa no Sudeste Goiano, por meio da luta pela terra e da efetivação dos assentamentos rurais como expressões (i)materiais desta (re)territorialização. No âmbito da pesquisa qualitativa, desenvolvemos pesquisa teórica, documental e de campo, com a realização de entrevistas semiestruturadas e registros fotográficos. Compreendemos que a luta pela terra foi um momento importante para a (re)territorialização camponesa no Sudeste Goiano, sendo os assentamentos uma expressão (i)material deste processo, onde os indivíduos e as famílias assentadas produzem seus territórios e territorialidades, no tempo histórico. Da apropriação inicial, passando pela produção de alimentos, a autoconstrução de suas moradias e a expressão das suas religiosidades, temos uma porção do espaço geográfico sendo transformada em território camponês. E isto é significativo em uma região goiana marcada pela agricultura capitalista especializada na exportação de produtos agrícolas. Nesta (re)territorialização, os camponeses assentados adquirem um trunfo para suas vidas, que é o território.

Palavras-chave: (Re)territorialização. Território. Territorialidades. Assentamentos rurais. Sudeste Goiano.

\section{Résumé}

L'objectif de cet article est de comprendrele processus de (re)territorialisation paysannedans le sud-est de l'état de Goiás,au moyen de la lutte pour la terre et del'implémentation desassentamentos rurauxen tant qu'expressions (i)mmatérielles de cette (re)territorialisation. Dans le cadre de la recherche qualitative, nous avons développé une recherche théorique, documentaire et de terrain, à l'aide d'entretiens demi-structurés et d'une documentation photographique. Nous avons compris que la lutte pourla terrea été un moment important pour la (re)territorialisationpaysannedans le sud-est de Goiás, 
et les assentamentos sont une expression (i)mmatériellede ce processus, puisqueles individus et les famillesinstallésproduisent leurs territoires et territorialités dans le temps historique. Depuis l'appropriation initiale, en passant par la production d'aliments, l'autoconstruction de leurs maisons et l'expression de leurs religiosités, nous avons une parcelle de l'espace géographique transformée en territoire paysan. Cela est important dans une région de Goiás marquée par l'agriculture capitaliste spécialisée dans l'exportation de produits agricoles. Au cours de cette (re)territorialisation, les paysans installés acquièrent un atout pour leurs vies, c'est-à-dire le territoire.

Mots-clés: (Re)territorialisation. Territoire. Territorialités. Assentamentos ruraux. Sudest de Goiás.

\section{Introdução}

No Brasil e em Goiás os assentamentos rurais surgiram nos anos 1980, resultantes da pressão dos trabalhadores rurais sobre o Estado (em suas escalas de governabilidade, sobretudo federal e estaduais), organizados em movimentos sociais, federações de trabalhadores agrícolas e sindicatos de trabalhadores rurais, realizando ocupações de terras, de órgãos públicos e formando acampamentos. A (re)conquista da terra acontece no interior de uma questão agrária nacional latente, cujo cerne se localiza na expansão geográfica contraditória e desigual do capitalismo nos espaços rurais brasileiros, centrada em duas lógicas relacionadas: a modernização tecnológica e a mudança nas relações de trabalho nas grandes e médias propriedades rurais (assalariamento, trabalho temporário) e a desterritorialização dos camponeses e trabalhadores rurais, por causa da concentração fundiária, sendo que muitos deles se (re)territorializaram nos espaços urbanos ou nos assentamentos.

Na Região Sudeste Goiano o cenário é semelhante: de um lado, o desenvolvimento de uma agricultura capitalista, baseada em empresas rurais familiares (comandadas por sulistas, em grande medida), especializadas na produção e exportação de soja, milho, sorgo, algodão, feijão, café, trigo e cana de açúcar; de outro lado, a resistência dos sujeitos que reproduzem a agricultura camponesa, que é recriada nos assentamentos rurais, também frutos da luta pela terra organizada pelos sindicatos de trabalhadores rurais, pela Federação dos Trabalhadores Rurais na Agricultura do Estado de Goiás (FETAEG), pelo Movimentos dos Trabalhadores Rurais Sem Terra (MST), 
entre outros mediadores. Estes assentamentos são a expressão concreta e simbólica da (re)territorialização camponesa.

Nesse sentido, o objetivo deste artigo é compreender o processo de (re)territorialização camponesa no Sudeste Goiano, por meio da luta pela terra e da efetivação dos assentamentos como expressões (i)materiais desta (re)territorialização.

Foram escolhidos o Assentamento João de Deus (município de Silvânia, 1987), Assentamento São Sebastião (Silvânia, 1997), Assentamento Olga Benário (Ipameri, 2005), Assentamento Madre Cristina (Goiandira, 2009), Assentamento Buriti (Silvânia, 2009) e Assentamento Maria da Conceição (Orizona, 2010). A seleção dos assentamentos se deu por uma opção investigativa em abranger, no Sudeste Goiano, todos os assentamentos criados até aquele momento (2015). O intuito foi encontrar características comuns e diferentes entre eles e os indivíduos que neles vivem. ${ }^{\text {ii }}$

A título de esclarecimento, foram distintos mediadores que organizaram os assentamentos que pesquisamos: o Sindicato de Trabalhadores Rurais de Silvânia (Assentamento João de Deus e o São Sebastião, juntamente com a Federação dos Trabalhadores Rurais na Agricultura do Estado de Goiás - FETAEG); o Movimento dos Trabalhadores Rurais Sem Terra - MST (Assentamento Olga Benário e Madre Cristina); o Movimento de Volta do Trabalhador ao Campo - MVTC (Assentamento Buriti) e, novamente, a FETAEG (Assentamento Maria da Conceição).

Nesta pesquisa qualitativa estruturamos a pesquisa teórica, abrangendo leituras que tratam da des-re-territorialização (processo TDR), do território e das territorialidades, como Saquet (2005; 2009; 2014; 2015 [2011]); autores que discutem o campesinato (em níveis econômicos e culturais), a exemplo de Woortmann (1990), Shanin (2008) e Sabourin (2009); pesquisadores que explicam as ocupações e a luta pela terra no Brasil, que são Fernandes (2000; 2015) e Fernandes, Welch e Gonçalves (2014); teóricos que versam sobre Goiás, sua economia, sua questão agrária e seus assentamentos, como Pessoa (1999) e Arrais (2013); e, finalmente, leituras sobre o Sudeste Goiano e as transformações no seu espaço rural, como Matos (2011) ${ }^{\mathrm{iii}}$. No campo metodológico fizemos leituras acerca da importância da pesquisa teórica e de campo, baseados em Alentejano e Rocha-Leão (2006), Mendes e Pessôa (2009), Santos e Pessôa (2009) e Marafon (2009); sobre amostragem lemos Ramires e Pessôa (2013) e sobre registros fotográficos, L'Estoile e Sigaud (2006) e 
Martins (2009) ${ }^{\mathrm{iv}}$. Estas leituras forneceram o aporte necessário para a interpretação do real, conforme argumentam Mendes e Pessôa (2009).

Na pesquisa documental consultamos o site do Instituto Nacional de Colonização e Reforma Agrária (INCRA) e o blog da Superintendência Regional de Goiás deste mesmo órgão público. Além disso, em setembro de 2015, consultamos os processos de criação dos assentamentos, na sede do INCRA em Goiânia.

E a pesquisa de campo abarcou as entrevistas semiestruturadas (com questões abertas e fechadas) e os registros fotográficos. De modo geral, o ir a campo significa o momento da articulação entre a teoria e a empiria (ALENTEJANO; ROCHA-LEÃO, 2006), a ocasião de experienciação e tensionamento dos conceitos e teorias e de produção de informações (MARAFON, 2009) e também a oportunidade que o pesquisador tem de se relacionar com os sujeitos da pesquisa em seus lugares de vida, de trabalho e de representação (SANTOS; PESSÔA, 2009). Pelos registros fotográficos (os captados pelo pesquisador ou as fotografias antigas) se institui esta mesma relação de troca (L'ESTOILE; SIGAUD, 2006), sobretudo pelo entendimento de que as fotografias são um conjunto narrativo de histórias (MARTINS, 2009) e fazem parte de uma memória individual e coletiva.

A nossa amostragem foi não probabilística que, de acordo com Ramires e Pessôa (2013), funciona por acessibilidade ou conveniência, quando o pesquisador seleciona os elementos a que tem acesso e admite que possam representar o universo (população).

Dessa forma, entrevistamos 123 pessoas nos assentamentos, uma por lote/parcela, em um trabalho semanal, majoritariamente aos sábados, entre dezembro de 2014 e junho de 2015, percorrendo distâncias entre 50km e 200km da cidade de Pires do Rio, que era o ponto de partida do pesquisador. Foram 13 entrevistas no Assentamento Maria da Conceição (de um total de 16 famílias assentadas), 14 no Assentamento Madre Cristina (16 famílias assentadas), 55 no Assentamento Olga Benário (84 famílias assentadas), sete no Assentamento João de Deus (16 famílias assentadas), 27 no Assentamento São Sebastião (33 famílias assentadas) e também sete no Assentamento Buriti (14 famílias assentadas). Desse total, foram gravadas e transcritas 63 entrevistas. Optamos por uma transcrição fiel ao que os sujeitos falaram, embasados em Whitaker (2002, p. 16) que salienta: "Os transcritores julgam possível reproduzir uma pronúncia original usando 
erros ortográficos. Quando um sujeito fala, ele está falando, não está escrevendo. Não está, assim, cometendo erros ortográficos".

Entre os meses de maio e agosto de 2016 retornamos em alguns assentamentos para conversas informais, registros fotográficos e algumas entrevistas (cerca de quatro, além das 123 supracitadas). Em todo o trabalho de campo contamos com a colaboração do senhor Roberto, assentado em Orizona, que nos conduzia semanalmente e nos apresentava em cada lote de terra que chegávamos ${ }^{\mathrm{v}}$. Isto contribuiu, com toda certeza, para a realização desta pesquisa, que será apresentada nos itens seguintes, começando com uma sucinta apresentação dos entrevistados e a localização dos assentamentos.

\section{Caracterização dos sujeitos da pesquisa e localização dos assentamentos}

Os indivíduos e as famílias que estão assentadas possuem diversas trajetórias espaciais. Discriminaremos, na sequência, as naturalidades estaduais e municipais (somente para aqueles nascidos em Goiás) dos nossos entrevistados, separando por assentamento:

1) Assentamento João de Deus: todos são naturais de Goiás, especialmente dos municípios de Silvânia, Morrinhos, Uruana e Vianópolis;

2) Assentamento São Sebastião: são predominantemente goianos (municípios de Silvânia, Vianópolis e Luziânia), embora tenham pessoas do Maranhão e do Rio Grande do Sul;

3) Assentamento Olga Benário: de todos os assentamentos este é o que possui maior número de pessoas de lugares diferentes (Goiás, Minas Gerais, Bahia, Distrito Federal, Amazonas, Pará, São Paulo e Mato Grosso). São naturais dos seguintes municípios goianos: Ipameri, Jussara, Morrinhos, Piracanjuba, Cidade de Goiás, Pires do Rio, Itaguaru, Urutaí, São Simão, Itaguari, Goiânia, Iporá, Itapuranga, Santa Cruz de Goiás, Inhumas, Jandaia, Santa Helena de Goiás, Quirinópolis, Itapirapuã, Campo Alegre de Goiás, Aruanã, Itaberaí, Niquelândia e Aurilândia;

4) Assentamento Madre Cristina: são, em sua maioria, de Goiás (Ipameri, Inhumas, Santa Cruz de Goiás, Urutaí, Goiandira, Mossâmedes, Morrinhos, Uruaçu, Ceres e Goiânia), além do Ceará e de Minas Gerais;

5) Assentamento Buriti: são goianos (Silvânia, Leopoldo de Bulhões e Buriti Alegre), mas há pessoas do Maranhão e do Piauí; 
6) Assentamento Maria da Conceição: a naturalidade predominante é de Goiás (Pires do Rio, Orizona, Cristalina, Jaraguá, Ipameri e São Bartolomeu), mas há pessoas de Minas Gerais.

Eles e elas são, portanto, migrantes, pois estiveram em trânsito pelos espaços geográficos e pelo tempo no intuito de conseguir melhores condições de vida (terra, emprego, renda, moradia, qualidade de vida, felicidade). Nestes itinerários partiram de um estado para outro, de um município para outro, do campo para a cidade e da cidade para o campo.

Lamentavelmente, a conquista da terra não assegura que estes processos migratórios terminaram, uma vez que a vida nos assentamentos também impõe dificuldades para os seus moradores, como o acesso às políticas públicas e aos recursos financeiros governamentais, à assistência técnica, à saúde e educação, a comercialização, a formação de grupos, a distância da sede do município, a qualidade da terra, entre outros problemas. Somado a isso, não podemos ignorar que muitos vão embora por decisão e vontade, por vislumbrarem oportunidades de vida mais sedutoras; porque não gostaram da vida no assentamento, frustrando, talvez, as suas idealizações; ou se cansaram de esperar a situação melhorar.

As passagens e paragens da luta pela terra incluem, por suposto, a vida nos acampamentos, sobretudo para os participantes do MST. Por exemplo, as famílias do Assentamento Olga Benário e do Assentamento Madre Cristina passaram por vários acampamentos goianos, a saber: Acampamento Vilmar de Castro (município de Jaupaci), Acampamento Padre Josimo (Pires do Rio), Acampamento Luiz Ório (Itaberaí), Acampamento Recanto da Paz (Itumbiara), Acampamento 17 de Abril (Bela Vista de Goiás), Acampamento Paulo Gomes e Anita Mantuano (ambos em Ipameri), Acampamento Gregório Bezerra (entre Caldas Novas e Pires do Rio), Acampamento Pequena Vanessa (Cidade de Goiás), entre outros. A parada se deu nos assentamentos, localizados na Região Sudeste Goiano, como mostra o mapa 1.

A existência desses assentamentos, na referida região, é fundamental para se contrapor à hegemonia da agricultura capitalista, para a (re)criação do modo de vida camponês e da agricultura camponesa, para a produção do território e das territorialidades, em um Goiás marcado por uma questão agrária própria, como discute o próximo tópico, após a exposição do mapa. 
Mapa 1 - Localização dos assentamentos no Sudeste Goiano

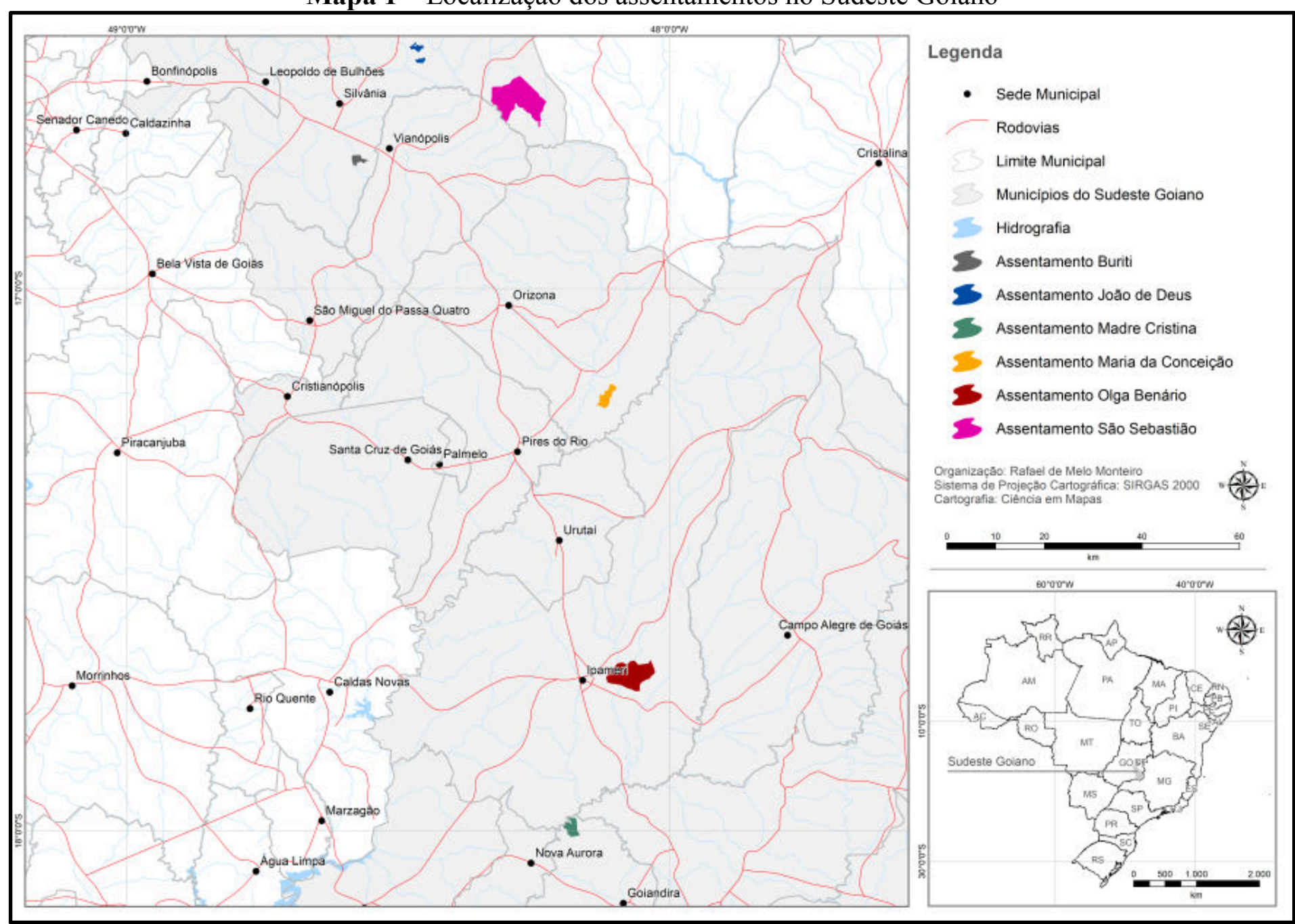

Organizado por: MONTEIRO, Rafael de M. (2019). 


\section{A questão agrária em Goiás e sua relação com a história de vida dos/as assentados/as}

No século XIX o estado de Goiás passou por uma mudança em sua organização espacial, social e econômica por causa do declínio da exploração do ouro de aluvião e da aposta na agricultura de autoconsumo e na pecuária extensiva como novas atividades econômicas. Com o tempo, se consolidou o transporte de gado pelas estradas boiadeiras, rumo à Região Sudeste, e a exportação de couros, peles, café e algodão (PESSOA, 1999).

O espaço rural goiano tinha a fazenda como modelo de organização social, baseada na autossuficiência e na poliatividade, com o cultivo de mandioca, a produção de leite e o uso da banha de porco para fazer sabão, conforme destaca Arrais (2013). O coronel era, nesta época, uma figura que representava poder e autoridade, na escala local, estadual e mesmo federal. Para ele trabalhavam e dele dependiam vaqueiros, sitiantes, camaradas e jagunços. E a relação de trabalho predominante, da ocupação do estado no século XVIII até o início do século XX, era a agregação. Por causa disso se interiorizou no imaginário dos trabalhadores rurais goianos a concepção de que a terra estava alheia ao seu domínio, pois ela era sempre um bem do coronel/fazendeiro/patrão (PESSOA, 1999).

Ao que parece, esta compreensão não definhou. A figura do fazendeiro/patrão permanece como símbolo de poder e autoridade, gerando medo no trabalhador, mesmo quando ele não está mais trabalhando como assalariado. Prova disso é que, no Assentamento Madre Cristina, uma senhora relatou:

\footnotetext{
Um ano e meio depois que a gente veio pra cá a gente saía e ainda ficava naquela preocupação [...] "Eu tenho que 'voltá' porque senão o patrão vai 'chegá' lá e vai tá as coisa fora do lugar, e aí? 'Vô' 'ganhá' rua”! (Entrevistada $9^{\text {vi }}$ sem informação de idade, Assentamento Madre Cristina/Goiandira/GO, 21/05/2016).
}

Os anos de 1920/40 trouxeram uma valorização fundiária por conta da expansão da estrada de ferro em solo goiano. Adiante, a modernização da agricultura (anos 1960/70), feita pelo Estado, por grandes proprietários, grupos agroindustriais e grupos internacionais, resultou em mudanças técnicas (uso do trator, de agrotóxicos, de sementes e insumos químicos), redução dos cultivos tradicionais (o arroz, por exemplo), ampliação do assalariamento e da concentração fundiária, perda da biodiversidade, especialização da produção para exportação, destruição da pequena propriedade e desterritorialização de 
posseiros, pequenos proprietários, parceiros, entre outros (PESSOA, 1999; ARRAIS, 2013).

Todos esses efeitos negativos puderam ser testemunhados, como explica um dos nossos entrevistados:

\begin{abstract}
Lá nos anos 70, 80 até meados dos anos [19]90 o município de Niquelândia era de boa produção e de alta produção de arroz, milho, feijão, tudo que era legume, cereais alimentícios. Porém entrou a Níquel Tocantins lá e comprou aquelas terras, tomou muita terra e eu conheço muitas fazendas lá que fora tomada a bico de carabina [com arma de fogo] [...] muita gente que ficou sem suas casas que eles colocaram fogo e queimou [...] alguns que tinha documento eles ia lá e comprava, pagava uma "mixaria" [pouco dinheiro] e tirava, mas aqueles que não tinham documento era expulso. Com a evolução que foi indo, foi surgindo a fome porque expulsou aquele povo que produzia, diminuiu a produção [...] aquele povo que fora expulso das suas terrinha foram jogados lá dentro da cidade, ali naquela periferia da cidade [...] quando a gente chegava na cidade já via aquele tanto de barraquinha de palha, de capim, de tábua, de papelão, de plástico. (Entrevistado 1, 56 anos, Assentamento Olga Benário/Ipameri/GO, 22/03/2015).
\end{abstract}

Esta narrativa traz o posseiro como figura central, aquele que não tem o documento da sua terra de trabalho, onde ele vive há anos, e é expulso dela, com violência física e simbólica por quem, normalmente, não tem direito sobre ela, mas que quer cercala e se proclamar como o dono. $\mathrm{O}$ posseiro não se vincula diretamente ao patrão/fazendeiro, mas também foi desterritorializado pela expansão capitalista no espaço rural. Por todos esses problemas gerados é que foi necessário que os trabalhadores rurais se organizassem na luta pela terra e nas ocupações de fazendas e órgãos públicos.

De acordo com Fernandes (2000; 2015) e Fernandes, Welch e Gonçalves (2014) as ocupações são a principal forma de acesso à terra no Brasil. Em Goiás elas aconteceram a partir de 1980, de duas maneiras: a) como resistências isoladas ou de grupos em posses antigas; b) como uma ação organizada por mediadores, como os sindicatos de trabalhadores rurais, a Comissão Pastoral da Terra $(\mathrm{CPT})^{\mathrm{vii}}$, o Movimento dos Trabalhadores Rurais Sem Terra (MST), entre outros (PESSOA, 1999).

As pessoas decidem participar da luta pela terra, das ocupações e dos acampamentos na expectativa de atender as demandas imediatas da vida, da sobrevivência e da existência humana, como ter comida, renda, trabalho, terra e casa própria. Mais do que isso, ter um lugar próprio no mundo, digno, que possa servir de refúgio, sustentação, conforto e aconchego, depois de uma árdua caminhada pela vida e com o destino incerto (fora ou dentro da luta). Assim reflete Certeau (2014 [1980], p. 
170): “Caminhar é ter falta de lugar. É o processo indefinido de estar ausente e à procura de um próprio".

Não por acaso um dos nossos entrevistados reforçou a razão pela qual participou de uma ocupação. Ele foi bastante direto em suas motivações:

\begin{abstract}
Nós ocupamos essa terra pra adquirir ela pra nós trabalhar e sobreviver porque nós tava morrendo... morrendo de fome, morrendo de falta de moradia, morrendo de falta de tudo, porque quando cê tem fome, num tem saúde, num tem vida digna, num tem prazer, num tem alegria, num tem nada, só "desvaneio" na vida (Entrevistado 1, 56 anos, Assentamento Olga Benário/Ipameri/GO, 22/03/2015).
\end{abstract}

Entre os anos 1980/90 várias ocupações de terras ocorreram em Goiás, na Fazenda São João do Bugre/Estiva (município de Goiás), Fazenda Serra Branca/Boa Vista (Itapirapuã), Fazenda Mosquito (Goiás), que se tornou o primeiro assentamento goiano, em 1986; Fazenda Pedregulhos/Três Pontes (Jataí), Fazenda Rio Paraíso (Jataí), Fazenda Retiro (Goiás), Fazenda Velha (Itapirapuã), Fazenda Rancho Grande (Goiás), Fazenda Vereda Bonita (Goiás), Fazenda São João da Lavrinha (Goiás), Fazenda Três Barros (Cristalina), entre outras (PESSOA, 1999). Muitos assentamentos surgiram dessas ocupações e, principalmente, elas se tornaram um aprendizado político aos trabalhadores rurais organizados ${ }^{\text {viii }}$.

Os assentamentos se territorializaram no Sudeste Goiano desde 1987 (Assentamento João de Deus), embora o primeiro assentamento do MST, na referida região, tenha se concretizado no ano de 2005 (Assentamento Olga Benário). De acordo com Matos (2011) coexistem a agricultura capitalista, centrada em empresas rurais familiares, com produção focada em soja, milho, cana de açúcar, café, trigo, algodão, sorgo e feijão, presente em municípios como Catalão, Campo Alegre, Ipameri, Orizona, Silvânia, Vianópolis e Gameleira de Goiás e a agricultura camponesa, desenvolvida em comunidades rurais e nos assentamentos, produzindo também alimentos, moradias e expressando religiosidades, processos que indicam a efetivação da (re)territorialização.

\title{
As expressões concretas e simbólicas da (re)territorialização camponesa
}

Um primeiro aspecto que precisa ser ressaltado, para o entendimento da (re)territorialização, é a apropriação inicial das terras pelas famílias e indivíduos (coletividades). Certamente, é um momento de alívio, após toda a disputa política e 
resistência que viveram. A decisão de lutar pela terra demonstra uma necessidade urgente ou um forte desejo dessas pessoas, a ponto de enfrentarem o preconceito da sociedade, a violência, o próprio sentimento de vergonha, a negligência estatal, a fome, entre outras coisas. Portanto, a (re)inauguração da vida se apresenta na paisagem, como na fotografia 1, com duas crianças brincando em uma lavoura de feijão, cultivada pouco depois que a sua família foi assentada, entre os anos 1997/98, no Assentamento São Sebastião.

Fotografia 1 - Assentamento São Sebastião/Silvânia/GO: a lavoura de feijão

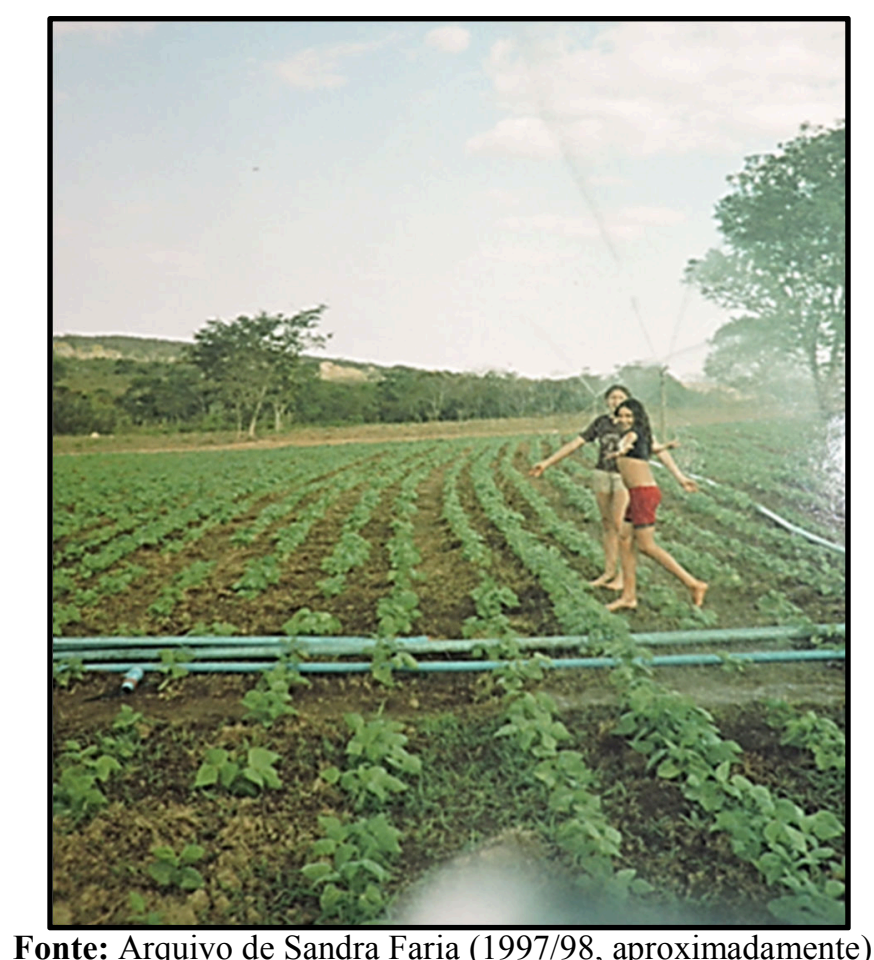

Como argumenta Saquet (2005; 2009; 2014; 2015 [2011]) a territorialização é a apropriação social de um fragmento do espaço, por meio das regras, das normas, das condições naturais, do trabalho, das técnicas e tecnologias, das redes de circulação e de comunicação, das conflitualidades, diferenças, desigualdades e identidades, determinadas historicamente. Esse processo de des-re-territorialização (TDR) ${ }^{\mathrm{ix}}$ contribui com a produção do território e se refere à mobilidade dos indivíduos (como força de trabalho e/ou para suprir necessidades, desejos, anseios e sonhos) e às mudanças/permanências nos arranjos espaciais (no campo e na cidade).

O cultivo da terra é uma expressão importante da (re)territorialização. Nos assentamentos, a produção camponesa combina o sistema pasto-gado-leite (principal 
sistema produtivo), as frutas (banana, abacaxi, maracujá, melancia, laranja, mamão, acerola, manga, uva, mexerica, abacate, limão e banana agroecológica), as hortaliças e verduras (pimenta, abóbora, pepino, açafrão, guariroba, quiabo, jiló, alface, batata, cará, marimba), o cultivo de milho, a criação de galináceos, a plantação de mandioca, a criação de suínos. Também fazem queijo, farinha de mandioca, requeijão, rapadura, melado (derivados), doces, geleias, quitandas, vendem gado de corte, produzem fumo, mel, criam carneiros, perus, bodes, peixes, cultivam eucalipto (outros) e, por fim, produzem arroz, feijão, soja, café (grãos) e cana de açúcar, como apresenta o gráfico 1.

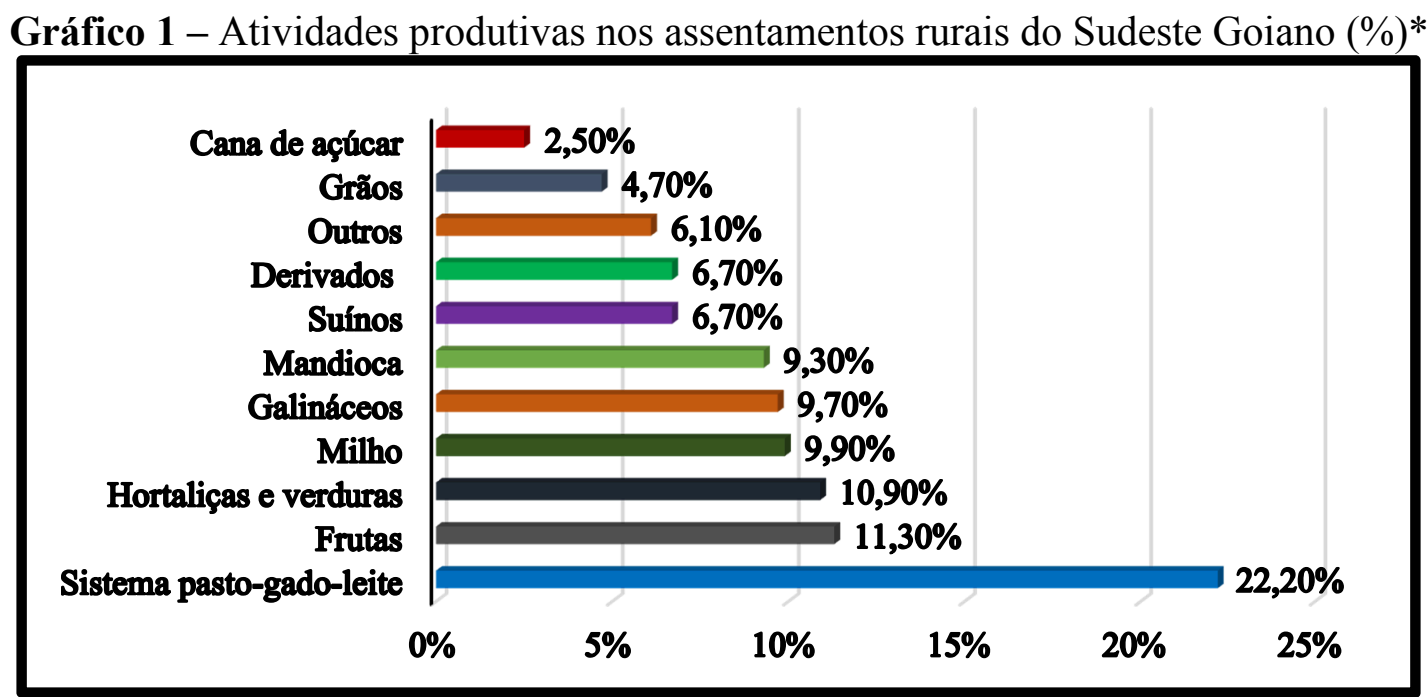

Fonte: Pesquisa de campo (dez. 2014 - jun. 2015)

Elaborado por: MONTEIRO, Rafael de M. (2015)

* Os entrevistados responderam, livremente, as atividades desenvolvidas nos seus lotes, somando 577 citações. As porcentagens apresentadas se referem a essas citações.

A produção é para o próprio consumo e para a comercialização, especialmente do leite, como mostra o gráfico 2 .

Estas vendas são feitas para laticínios (como, por exemplo, o Piracanjuba, localizado em Bela Vista, que compra o leite no Assentamento São Sebastião); efetivam vendas particulares nas ruas, praças e nas casas, em cidades como Ipameri, Silvânia, Goiandira, Catalão, Pires do Rio e Vianópolis; também vendem nos mercados locais (panificadoras, lanchonetes e supermercados); e nas feiras livres. Vendem, ainda, hortaliças, leite, ovos, suínos, quitandas e rapaduras por encomendas no interior dos assentamentos; negociam com cooperativas, em especial no caso do Assentamento João de Deus, que vende seu leite para a Cooperativa Agropecuária Mista de Produtores Rurais 
de Silvânia (COOPERSIL); com as Centrais de Abastecimento, predominantemente por parte do Assentamento Buriti, que vende para o CEASA de Anápolis e Goiânia. Finalmente, vendem para os atravessadores, que compram pimentas e frangos e para a Companhia Nacional de Abastecimento (CONAB), conforme o gráfico 3.

Gráfico 2 - Produtos comercializados pelas famílias camponesas (\%)*

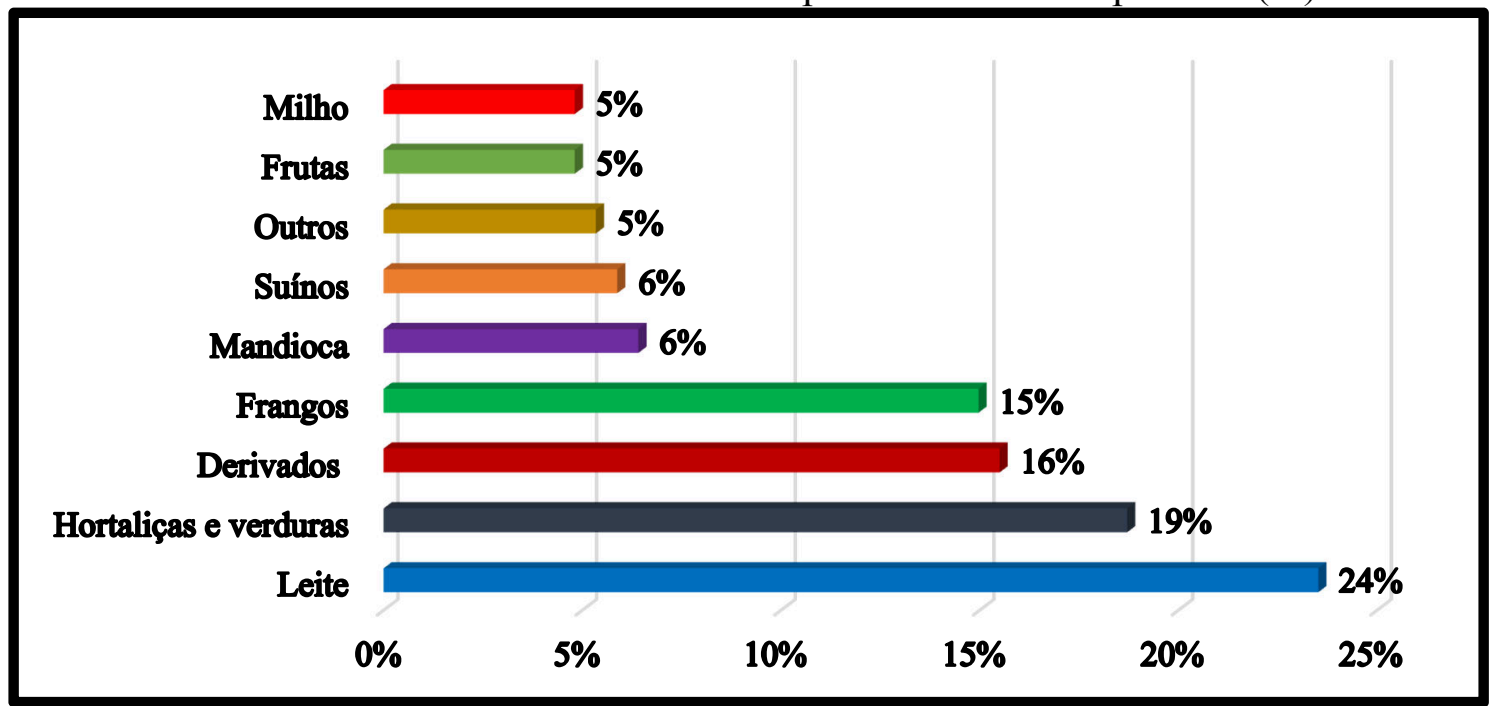

Fonte: Pesquisa de campo (dez. 2014 - jun. 2015)

Autor: MONTEIRO, Rafael de M. (2015)

* Do mesmo modo como no gráfico 1, neste as porcentagens foram feitas a partir de um total de 187 citações de produtos comercializados.

Gráfico 3 - Destinação dos produtos comercializados (\%)

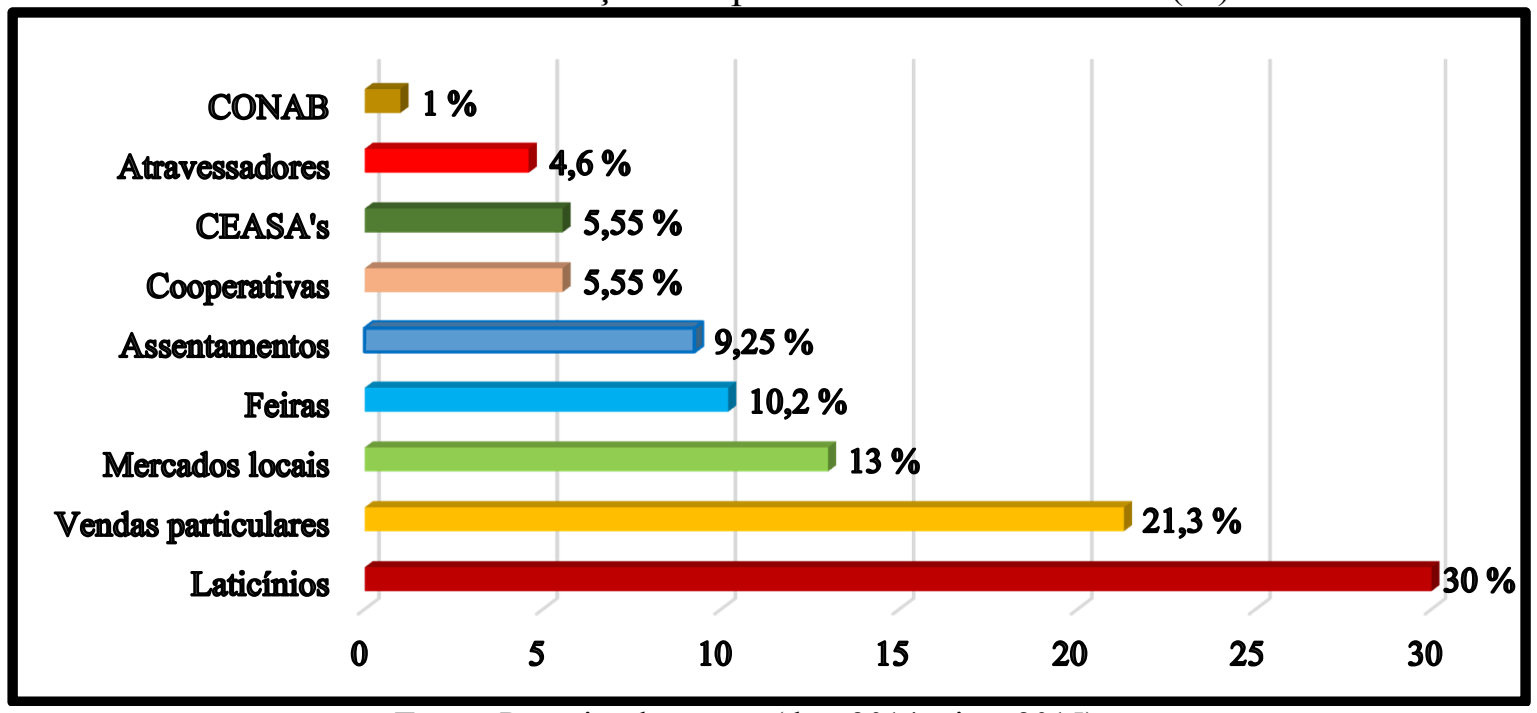

Fonte: Pesquisa de campo (dez. 2014 - jun. 2015)

Elaborado por: MONTEIRO, Rafael de M. (2015) 
Com a conquista da terra, as famílias se tornaram relativamente independentes no trabalho, embora muitos ainda trabalhem fora para complementar a renda, destacando a dicotomia entre trabalhar para si e trabalhar para os outros. O território se tornou um trunfo, por meio do qual o trabalho familiar é realizado e o ideal de liberdade é reforçado. Estes aspectos configuram a campesinidade (WOORTMANN, 1990) e o modo de vida camponês (SHANIN, 2008).

Vários entrevistados expressam uma opinião positiva sobre a vida nos assentamentos. Selecionamos um relato para relacionar com essa afirmação:

Em vista do que eu era eu tô rico, pela reforma agrária [...] porque eu não tinha nada na vida, hoje em dia tenho. [...] Eu trabalhava, roçava pasto para os outros, capinava, fazia de tudo, plantava banana, colhia banana, hoje em dia já não preciso trabalhar mais pros outros porque eu já tô cuidando das minhas coisas (Entrevistado 11, 58 anos, Assentamento Olga Benário/Ipameri/GO, 08/03/2015).

Assim que são assentadas as famílias improvisam suas moradias. Com o tempo, constroem suas casas, utilizando recursos financeiros governamentais e/ou recursos próprios. Surgem edificações de toda ordem e tipologia: de alvenaria, de lona, de madeira, com estruturas, tamanhos e acabamentos diferentes. Estas autoconstruções são feitas pelo trabalho e pela energia destas pessoas. Possuir uma moradia é bastante significativo para quem morava de aluguel, habitava casas precárias e, nos acampamentos, ficou muito tempo em barracas de lona. Ter a casa é ter um referente espacial, contar com um endereço no mundo, uma estabilidade desejada; ter onde habitar traduz uma conquista social vital: é morar no melhor lugar que já se morou na vida, como ouvimos do casal que aparece na fotografia 2.

Como menciona Pessoa (1999), tornar-se dono de um lote de terra e de uma casa é (re)construir um espaço de tranquilidade, de repouso, de recuperação e de hospitalidade. Para reforçar esta ideia, selecionamos um depoimento gravado no Assentamento Madre Cristina, no qual nossa entrevistada enuncia:

Eu sonho com uma casa, num é luxuosa não, só conforto. Eu queria o meu quarto, um quarto pros meus filhos, um quarto pra mim colocar uma visita quando chegar, minha sala, minha cozinha, minha varanda, de serviço, bem arrumadinha, pra mim colocar minha máquina, meu tanquinho [de lavar as roupas] pra trabalhar, área externa pra gente sentar no final do dia pra lembrar como é que foi o dia (Entrevistada 9, sem informação de idade, Assentamento Madre Cristina/Goiandira/GO, 21/05/2016). 
Fotografia 2 - Assentamento Olga Benário/Ipameri/GO: a casa própria

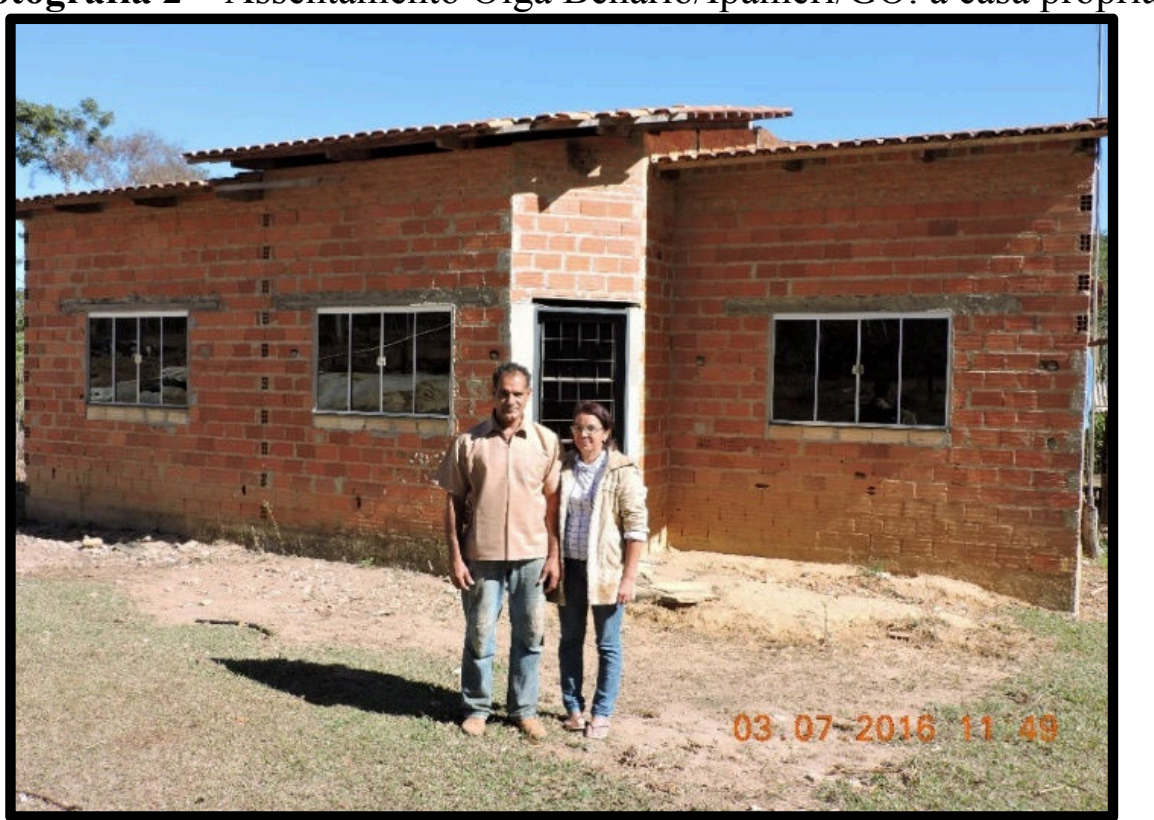

Fonte: Arquivo pessoal (07/2016).

Por último, outro aspecto da (re)territorialização que queremos destacar é a expressão das religiosidades. Nos assentamentos pesquisados predominam o catolicismo $(47,8 \%)$ e o (neo)pentecostalismo (42,6\%), além das pessoas que frequentam cultos e missas, as que são espíritas, presbiterianas ou que não possuem religião.

No âmbito do (neo)pentecostalismo temos a influência da Assembleia de Deus, Congregação Cristã no Brasil, Igreja Cristã Manancial, Igreja de Cristo, Igreja Universal do Reino de Deus, Igreja Mundial do Poder de Deus, Igreja Deus é Amor e Igreja Fonte da Vida. Além da influência simbólica, a Assembleia de Deus possui uma sede no Assentamento Olga Benário. Do mesmo modo, mas com outro sentido, no Assentamento São Sebastião as famílias edificaram uma capela em homenagem a Nossa Senhora Aparecida, pois prometeram isso caso conquistassem a terra (Fotografia 3).

A interpretação acerca das religiosidades é complexa. Elas podem ser compreendidas como uma autoridade que estrutura um consentimento profundo entre as pessoas que professam a mesma fé (CLAVAL, 1979); elas estabelecem laços e relações interpessoais (nos cultos, nas missas e nas festas religiosas) e, simultaneamente, reforçam as noções de submissão e obrigação entre os camponeses brasileiros (o pagamento do dízimo, por exemplo) (SABOURIN, 2009); constroem uma identidade individual e coletiva que delimita uma fronteira simbólica com o Outro (que pode ser o mundo, o 
demônio, a bebida, a festa); podem direcionar ou obscurecer os processos territoriais, que envolvem, por exemplo, a organização política (SAQUET, 2015 [2011]).

Fotografia 3 - Sede da Assembleia de Deus e Capela de Nossa Senhora Aparecida

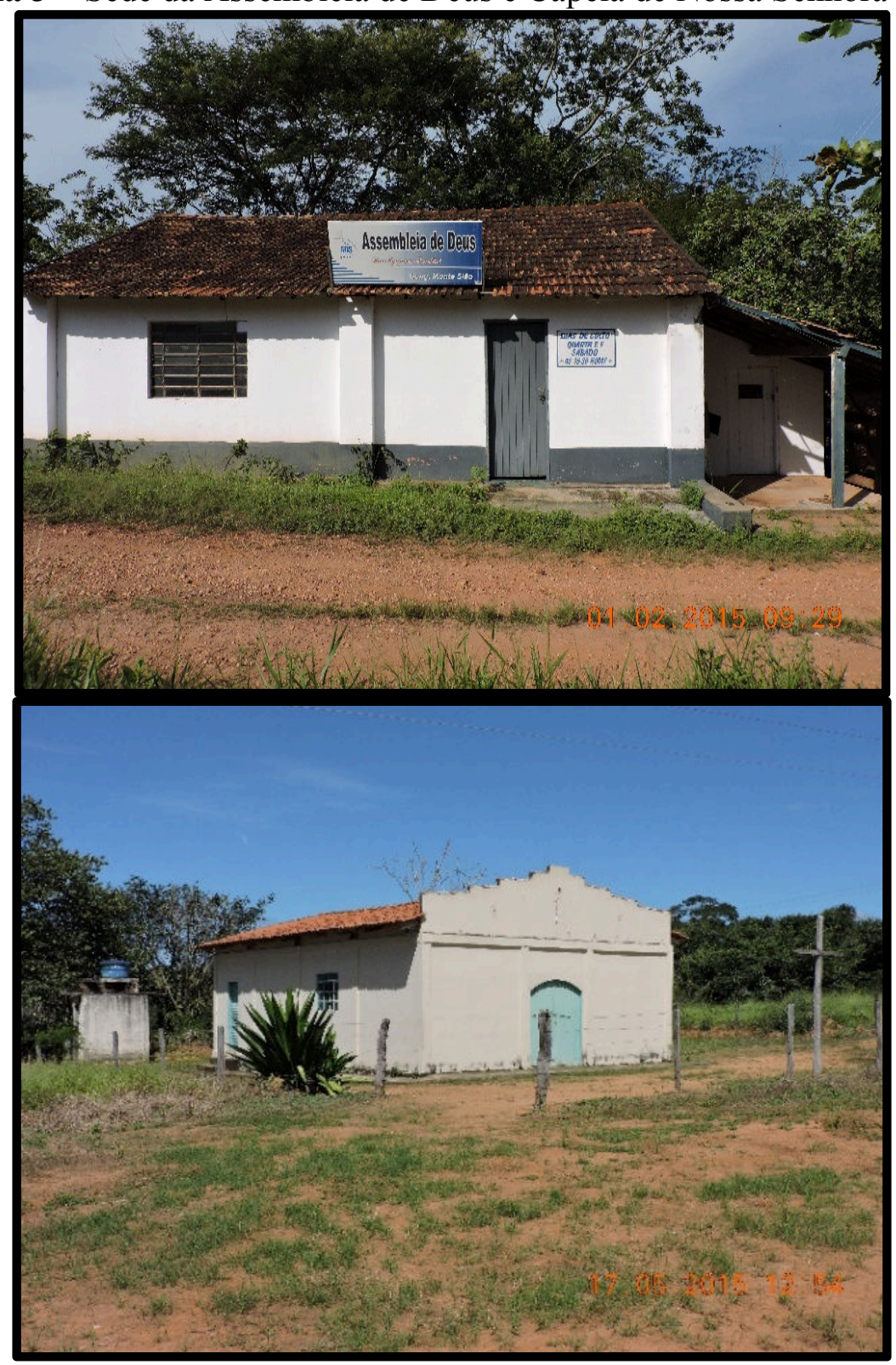

Fonte: Arquivo pessoal (02/2015 e 05/2015).

Em nossa concepção, as religiosidades, exercidas pelos seres humanos, estão envolvidas, no decorrer do tempo, na produção de códigos sociais e de significados, distintos e mesmo dicotômicos, como a crença na punição ou na bondade de Deus; a recusa do mundo, o isolamento familiar e espiritual e o desejo por bens materiais cuja conquista tem a mediação divina; a obrigação com Deus e o agradecimento à Ele; a ação 
do Diabo, entre outros. O primeiro trecho, por exemplo, mostra a noção de punição e castigo que um camponês tem acerca do divino; o segundo aponta a submissão e resignação que as pessoas precisam ter, de acordo com a entrevistada.

Eu tenho que prestar conta perante o trono de Deus. Lá tem dois livros abertos. Se o nome da pessoa num tiver lá, a palavra de Deus fala assim: "Afastai-vos de mim, maldito! Eu não te conheço, cê vai cair no fogo do eterno, aonde é que nunca mais tem liberdade". (Entrevistado 11, 58 anos, evangélico da Assembleia de Deus, Assentamento Olga Benário/Ipameri/GO, 08/03/2015).

Tudo que a gente consegue é através dele [Deus], num é através da gente. É com luta, tá certo, todo mundo tem que lutar, mas o Senhor dá saúde, abre as portas, cada um tem que carregar sua cruz, Cristo carregou a dele, nós também têm que carregar a nossa. (Entrevistada 32, 56 anos, evangélica da Igreja Cristã Manancial, Assentamento Olga Benário/Ipameri/GO, 25/01/2015).

Independente de algum juízo de valor, isso mostra uma vida simbólica que existe nos assentamentos e que também é uma forma de produção do território, pela apropriação simbólica do espaço.

\section{Considerações finais}

Gostaríamos de finalizar este artigo destacando que a luta pela terra foi um momento fundamental para a (re)territorialização camponesa no Sudeste Goiano, cuja expressão se deu com a formação dos assentamentos rurais, entre os anos 1987 e 2010. Ao longo do tempo, os indivíduos e as famílias assentadas foram construindo territórios camponeses inseridos em uma região goiana com forte presença da agricultura capitalista. Foram constituindo, da mesma maneira, suas territorialidades, concretas e simbólicas, gestadas nas relações humanas e com a natureza, pelo trabalho, pela produção de alimentos, pelas diferenças e identidades religiosas e pelas apropriações (i)materiais do espaço geográfico, territorializando-o no tempo histórico.

Estas pessoas tomaram consciência das contradições do mundo e, percebendo suas posições subalternas, decidiram lutar pela liberdade. A entrada na luta pela terra traduziu este anseio e a conquista da terra concretizou, ao menos de início, este desejo, ainda que em lugar diferente daquele de origem. Eles politizaram as suas vidas e, por isso, a (re)territorialização foi um processo educativo e que transformou uma porção do espaço 
geográfico do Sudeste Goiano em território camponês, um trunfo na vida destes sujeitos sociais.

\section{Notas:}

${ }^{1}$ Este texto resulta da tese de doutorado intitulada "As relações de poder e as territorialidades nos assentamentos rurais do Sudeste Goiano", financiada pela Fundação de Amparo à Pesquisa do Estado de São Paulo (FAPESP) - Processo no. 2013/10698-5, defendida no ano de 2017 junto ao Programa de PósGraduação em Geografia da Universidade Estadual Paulista (UNESP)/Câmpus Presidente Prudente, sob orientação do Prof. Dr. Marcos Aurélio Saquet.

ii No ano de 2016 foi criado o sétimo assentamento da região, denominado Ana Ferreira (Ipameri).

iiiRecomendamos a leitura das obras de Marcelo Rodrigues Mendonça e Maria Erlan Inocêncio, pois são também relevantes para o entendimento do espaço rural do Sudeste Goiano.

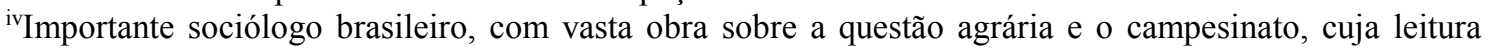
recomendamos aos que desejam compreender mais o tema.

'No carro estavam sempre o senhor Roberto, o pesquisador e seu pai, que não falhou uma semana sequer durante este período de entrevistas nos assentamentos.

vi Optamos por manter a ordem dos entrevistados conforme está na tese de doutorado mencionada anteriormente.

vii Entidade organizada por setores progressistas da Igreja Católica, surgida nos anos 1970, cuja orientação política era a Teologia da Libertação.

viiiNo estado de Goiás existem 456 assentamentos, com 26.241 famílias assentadas em 1.094.913 hectares, conforme o Relatório Dataluta (2016), cujos dados abrangem o período de 1979/2015.

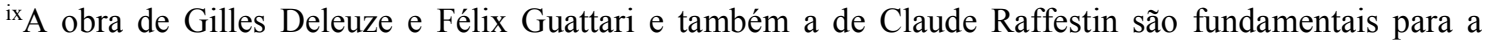
compreensão do processo TDR.

\section{Referências}

ALENTEJANO, Paulo Roberto; ROCHA-LEÃO, Otávio. Trabalho de campo: uma ferramenta essencial para os geógrafos ou um instrumento banalizado? Revista Boletim Paulista de Geografia, São Paulo, n. 84, 2006. p. 51 - 67.

ARRAIS, Tadeu A. Economia. In: . A produção do território goiano: economia, urbanização, metropolização. Goiânia: Editora da Universidade Federal de Goiás, 2013. p. 25-96.

CLAVAL, Paul. Espaço e poder. Tradução de Waltensir Dutra. Rio de Janeiro. Zahar, 1979 [1978].

CERTEAU, Michel de. A invenção do cotidiano: artes de fazer. 21. ed. Tradução de Ephraim Ferreira Alves. Petrópolis - RJ: Vozes, 2014 [1980].

FERNANDES, Bernardo M. A formação do MST no Brasil. Petrópolis - RJ: Vozes, 2000.

La cuestión de la reforma agraria en Brasil. Revista Interdisciplinaria de

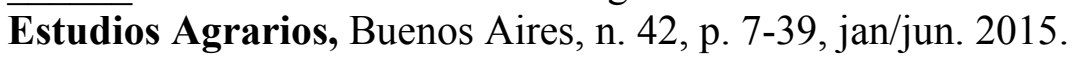


FERNANDES, Bernardo M.; WELCH, Clifford A.; GONÇALVES, Elienai C. Os usos da terra no Brasil: debate sobre políticas fundiárias. São Paulo: Cultura Acadêmica: Unesco, 2014. (Coleção Vozes do Campo).

L'ESTOILE, Benôit de; SIGAUD, Lygia. (Org.). Caderno de fotos: fotografia e pesquisa de campo. In: ___ Ocupações de terra e transformações sociais: uma experiência de etnografia coletiva. Rio de Janeiro: Editora da FGV, 2006. p. 19 - 28.

MARAFON, Gláucio José. O trabalho de campo como um instrumento de trabalho para o investigador em geografia agrária. In: RAMIRES, Júlio Césarde L.; PESSÔA, Vera Lúcia S. (Org.). Geografia e pesquisa qualitativa: nas trilhas da investigação. Uberlândia: Assis, 2009. p. 381 - 390.

MARTINS, José de S. Sociologia da fotografia e da imagem. São Paulo: Contexto, 2009.

MATOS, Patrícia Francisca de. As tramas do agronegócio nas "terras" do Sudeste Goiano. 357 f. Tese (Doutorado em Geografia) - Programa de Pós-Graduação em Geografia, Universidade Federal de Uberlândia, Uberlândia, 2011.

MENDES, Estevane de P. P.; PESSÔA, Vera Lúcia S. Técnicas de investigação e estudos agrários: entrevistas, registros de observações e aplicação de roteiros de entrevistas. In: RAMIRES, Júlio César de L.; PESSÔA, Vera Lúcia S. (Org.).

Geografia e pesquisa qualitativa: nas trilhas da investigação. Uberlândia: Assis, 2009. p. $509-537$.

PESSOA, Jadir de M. A revanche camponesa. Goiânia: Editora da UFG, 1999.

PESSÔA, Vera Lúcia S.; RAMIRES, Júlio Cesar de L. Amostragem em pesquisa qualitativa: subsídios para a pesquisa geográfica. In: MARAFON, Glaucio J. et al. (Org.). Pesquisa qualitativa em Geografia: reflexões teórico-conceituais e aplicadas. Rio de Janeiro: EdUERJ, 2013. p. 117-134.

RELATÓRIO DATALUTA - BANCO DE DADOS DA LUTA PELA TERRA, 2016. Disponível em: <http://www.fct.unesp.br/nera $>$. Acesso em: jul. 2017.

SABOURIN, Eric. Comunidades camponesas e organização social da produção. In: Camponeses do Brasil: entre a troca mercantil e a reciprocidade. Tradução de Leonardo Milani. Rio de Janeiro: Garamond, 2009. p. 29-77.

SANTOS, Joelma Cristina dos; PESSÔA, Vera Lúcia S. A pesquisa de campo nos canaviais do oeste paulista: o universo dos trabalhadores rurais entre a "sua forma de ser" e a exploração do seu "ser". In: RAMIRES, Júlio César de L.; PESSÔA, Vera Lúcia S. (Org.). Geografia e pesquisa qualitativa: nas trilhas da investigação. Uberlândia: Assis, 2009. p. 123 - 138.

SAQUET, Marcos Aurélio. Território e identidade. Anais do X Encontro de Geógrafos da América Latina, Universidade de São Paulo, 20-26 de março de 2005. p. 13869-13881. 
. Por uma abordagem territorial. In: SAQUET, Marcos A.; SPOSITO, Eliseu S.

(Org.). Territórios e territorialidades: teorias, processos e conflitos. São Paulo: Expressão Popular; UNESP: Programa de Pós-Graduação em Geografia, 2009. p. 7394.

Agricultura camponesa e práticas (agro)ecológicas: abordagem territorial histórico-crítica, relacional e pluridimensional. Mercator, Fortaleza, v. 13, n. 2, maio/ago, 2014. p. 125-143.

Por uma geografia das territorialidades e das temporalidades: uma concepção multidimensional voltada para a cooperação e para o desenvolvimento territorial. 2. ed. Rio de Janeiro: Consequência, 2015 [2011].

SHANIN, Teodor. Lições camponesas. In: PAULINO, Eliane T.; FABRINI, João E. (Org.). Campesinato e territórios em disputa. São Paulo: Expressão Popular, 2008. p. $23-47$.

WHITAKER, Dulce C. A. Sociologia rural: questões metodológicas emergentes. São Paulo: Letras à Margem, 2002.

WOORTMANN, Klaas. Com parente não se neguceia: o campesinato como ordem moral. Brasília, Anuário Antropológico 87, Editora Universidade de Brasília/Tempo Brasileiro, 1990. p. 11-73.

Recebido em 19/06/2018.

Aceito para publicação em 01/03/2019. 